\title{
A multidimensional approach to determinants of computer use in primary education: teacher and school characteristics
}

\author{
J. Tondeur, M. Valcke \& J. van Braak \\ Department of Educational Studies, Ghent University, Ghent, Belgium
}

\begin{abstract}
The central aim of this study was to test a model that integrates determinants of educational computer use. In particular, the article examines teacher and school characteristics that are associated with different types of computer use by primary school teachers. A survey was set up, involving 527 teachers from 68 primary schools in Flanders. A separate questionnaire was administered to information and communication technology (ICT) coordinators from the same schools to gather additional information about cultural and contextual school characteristics. The combined impact of both teacher and school characteristics was explored through a multilevel analysis. Besides the importance of school characteristics, the results reveal differential effects of specific characteristics on specific types of computer use. Cultural school characteristics for instance, such as the schools' openness to change and the availability of an ICT school policy plan, are positively related to the use of computers as a learning tool and to the adoption of ICT in view of basic computer skills. In contrast, no cultural school characteristic seem to be associated with the use of computers as an information tool. In a comparable way, teacher characteristics are associated with specific types of computer use, e.g. the variable gender. In general, male teachers report integrating computers more often. In this study, it appears that gender differences only exist in relation to the adoption of computers as an information tool. The results demonstrate that a multidimensional approach provides more insight into the characteristics affecting computer use.
\end{abstract}

Keywords computer use, multilevel modelling, primary education, school culture, school policies, teachers.

\section{Introduction}

Researchers are now beginning to face the critical characteristics associated with ICT (information and communication technology) integration, such as computer attitudes (van Braak et al. 2004; Albirini 2006), computer experience (van Braak 2001; Bovée et al. 2007) and computer training (Tan et al. 2003; Galanouli et al.

Accepted: 23 April 2008

Correspondence: Jo Tondeur, Department of Educational Studies, Ghent University, Henri Dunantlaan 2, B9000 Ghent, Belgium. Email: jo.tondeur@ugent.be
2004). However, current studies succeed only partly in explaining differences in the integration of educational computer use. One of the reasons for this might be that most researchers have investigated the influence of just a few characteristics on the integration process; there has been little overlap between these fields of interests. As a consequence, studies tend to ignore the complex systemic nature of ICT integration (Tang \& Ang 2002).

In addition, research focusing on ICT integration is generally limited to the study of factors at class level. Until now, little empirical studies have been set up that study the impact of school related factors. In our view, 


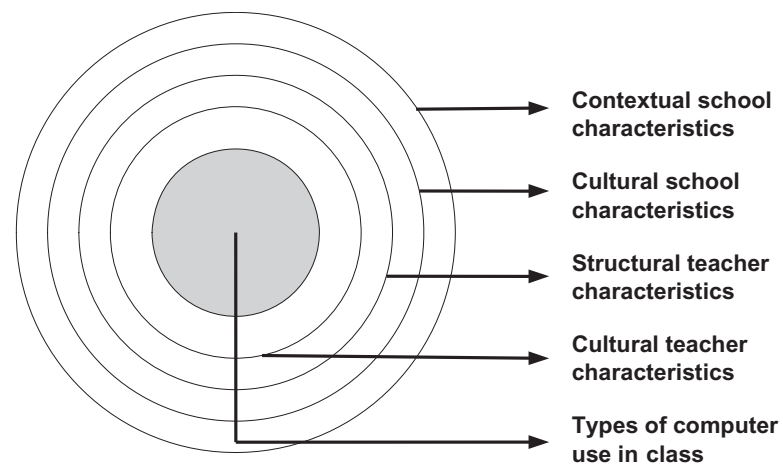

Fig 1 Conceptual model of the study, based on the structure of concentric circles by Veenstra (1999).

research has to investigate teacher and school characteristics in concurrence. The latter requires more advanced statistical techniques. For that reason, we explored the complex relationship between teacher and school characteristics and ICT integration by means of multilevel analysis. An essential advantage of this statistical technique is that it recognizes the hierarchical and/or clustered structure of variables in a multidimensional model (Rasbash et al. 2004). In this case teachers are clustered within schools. To ignore this relationship risks overlooking the importance of school effects.

Another difficulty is that ICT integration in education can be defined in different ways. On the base of a previous study (Tondeur et al. 2007a), we distinguish this between three different types of educational computer use: 'basic computer skills', 'the use of computers as an information tool' and 'the use of computers as a learning tool'. The main objective of this study is to determine teacher and school characteristics that help to explain the differences in implementing these three types of computer use.

There are many factors influencing computer use in education. A framework that helps structure this variety in processes and variables is therefore helpful. In the present study we adopt a framework that is based on concentric circles to organize the determinants of ICT integration (Veenstra 1999; Veenstra \& Kuyper 2004; Meelissen 2005). The model in Fig 1 was originally developed to illustrate differences in student achievement (Veenstra 1999) but is considered to be appropriate for this study.

The core of the model represents the dependent variable(s), the extent to which 'types of educational computer use' are being implemented. Further, we dis- tinguish two categories of variables both at the individual teacher level and at the school level. The teacher level includes a category of structural teacher characteristics and a category of cultural teacher characteristics. The structural characteristics such as 'computer experience' and 'gender', form the outermost circle. The cultural teacher characteristics are placed as an intermediate circle between the structural characteristics and the dependent variables. They comprise, among others, the 'teacher's beliefs about good education' and 'computer attitudes'. At school level, a similar distinction is made between contextual characteristics (e.g. infrastructure) and cultural school characteristics (e.g. leadership, ICT school policy). Our central aim is to test a model that integrates both cultural and structural characteristics when explaining differences in levels of ICT integration, both at individual teacher level and at school level. Following this framework, we can develop a deeper insight into the relationships between the influencing characteristics. Furthermore, this study explores the relationship between these characteristics on different types of computer use in primary education.

\section{Background}

Some researchers make a case for a more holistic approach to study innovations in schools such as ICT integration (Salomon 1990; Kennewell et al. 2000; Fullan 2001; Kozma 2003). They assume an integral, multidimensional relationship between computer use and a set of personal, pedagogical and organizational factors. In this respect, researchers are faced with the challenge of investigating the many influencing characteristics of ICT integration in conjunction with each other. In this background section, we review the empirical literature grounding the importance of the variables and processes that are presented in the five concentric circles of the present research framework. In particular we concentrate on studies that link these variables to the use of computers in education. Yet this list of factors cannot reflect the full complexity of ICT integration. The knowledge base presented in this paper is by no means definitive or exhaustive. Understanding one element leads to the necessity to understand the foundation on which that element rests, which in turn can lead to the discovery of other significant elements (Beach \& Lindahl 2004). First, we elaborate on the dependent variables. 


\section{Types of educational computer use}

ICT has ballooned to encompass many aspects of technological devices. However, in the present study, we centre on computers (laptop, desktop) as the centre technological tool, with or without peripheral devices. 'ICT integration' and 'the adoption of computer use' will be used as interchangeable concepts. In the literature, a range of definitions, classifications and typologies can be found to determine types of educational computer use (Tondeur et al. 2007a). Some studies determine computer use by reporting the time teachers and pupils spend using computers (e.g. O'Dwyer et al. 2004). In other studies, the focus is rather on the adoption of specific software applications (e.g. Kent \& Facer 2004). Although these studies are valuable, they hardly help to clarify the qualitative nature of educational use of computers. Only a limited number of studies centre on the instructional objectives pursued by integrating computer use. The study of Ainley et al. (2002) is an exception in this context since they focus on how ICT is used for learning and instruction. They differentiate between categories of educational computer use such as 'computers as information resource tools' and 'computers as authoring tools'. Similarly, Waite (2004) reported teachers' responses about the aims and uses of computers for literacy in primary schools.

Although each of the available studies enriches the whole picture of educational computer use, a comprehensive instrument that integrates types of computer use in the context of primary education is yet not available. Therefore, a prior study was set up to identify a typology of actual computer use in primary education (Tondeur et al. 2007a). The results suggest a threefactor structure: 'basic computer skills' (to develop pupils' technical computer skills), 'the use of computers as an information tool' (to research and process information) and 'the use of computers as a learning tool' (to practice knowledge and skills). In the present study, we relate these three types of computer use to teacher and school characteristics.

\section{Cultural teacher characteristics}

The individual teacher 'as a learner' is at the centre of educational change processes (Stoll 1999). Teacher experiences, beliefs, emotions, knowledge, skills, motivations, etc., interact within the learning context. Teach- ers' perceptions about and actions towards changing and developing their teaching methods are influenced by what they believe, as well as their knowledge (Fullan 2001). Their priorities, therefore, are extremely important. Each teacher experiences his or her own career pattern, which influences the desire to learn and the readiness to engage in educational innovation activities (Huberman 1988).

What kind of teacher characteristics affects the adoption of computer use? Many studies have focused on measuring the impact of computer attitudes (Shapka \& Ferrari 2003; van Braak et al. 2004; Bovée et al. 2007). Attitudes towards computers may be defined as specific feelings that indicate whether a person likes or dislikes using computers (Simpson et al. 1994). A general finding is that teachers adopting a more positive computer attitude are more likely to use computers in the class (van Braak et al. 2004). Other cultural teacher characteristics that can be connected to the educational use of ICT are 'innovativeness' and 'teachers' educational beliefs'. Innovativeness refers to the willingness to adapt to an innovation compared with others in the same social system (Rogers 1995). A high degree of innovativeness implies a clear knowledge about the innovation, favourable attitudes and an intention to adopt the innovation (van Braak 2001). The findings of van Braak et al. (2004) underpin the role of innovativeness as an important determinant to explain the use of computers in class.

It is also acknowledged that teachers' educational beliefs are associated with specific uses of computers in the classroom (Becker 2001; Ertmer 2005; Song et al. 2007). Several studies explain this by hypothesizing that teachers who use computers do so because their conceptions of using ICT fit into their existing teaching beliefs or belief system (Niederhauser \& Stoddart 2001). A variety of instruments are available to determine teachers' educational beliefs. Woolley et al. (2004) for instance developed the 'Teachers Beliefs Survey'. In their instrument, the dimension 'traditional teaching' mainly focuses on traditional approaches to the curriculum and assessment. The second dimension, 'constructivist teaching', embraces studentcentred approaches to teaching and learning. Current research shows that low-level computer use tends to be associated with teacher-centred practices, whereas high-level use tends to be associated with studentcentred or constructivist practices (Ertmer 2005). 


\section{Structural teacher characteristics}

Research about computing in education puts much emphasis on the 'gender issue' (Shashaani 1997; Volman \& Van Eck 2001; van Braak et al. 2004). For example, it was found that female teachers report significantly lower levels of educational computer use than their male counterparts (van Braak et al. 2004). Not all studies, however, show consistent results. Shapka and Ferrari (2003) found no gender differences in computer outcomes and argue that gender differences are gradually dissipating. Another structural teacher characteristic is 'computer experience'. Research showed that computers are more intensively used by teachers who have more years of computer experience (Shashaani 1997; Rozell \& Gardner 1999). Also 'age' is frequently related to computer use (e.g. Bradley \& Russell 1997). When controlled for computer experience however, class use of computers does not seem to be age-related (van Braak et al. 2004).

\section{Cultural school characteristics}

ICT integration can be seen as a specific case within the wider field of school improvement. Research set out to identify the factors influencing ICT integration showed that these same factors could be applied to school improvement in general (Otto \& Albion 2002; Dawson \& Rakes 2003). In this respect, an important factor is the development of a shared vision concerning the use of computers for teaching and learning (Hughes \& Zachariah 2001; Otto \& Albion 2002). It appears that teachers working in schools that are engaged in ICT planning are more likely to apply ICT in an innovative way (Kozma 2003). Analysis of the available research also reveals the importance of leadership in managing ICT integration. School principals are in a position to create the conditions to develop such a shared ICT policy. Several studies (e.g. Anderson \& Dexter 2000; Dawson \& Rakes 2003) support the claim that leadership promoting change is a key factor when it comes to merging ICT and instruction. Other school-related factors that can be connected to educational computer use are the degree of computer training (Galanouli et al. 2004) and ICT-related support (Lai \& Pratt 2004). Baylor and Ritchie (2002) conclude that training has an important influence on how well ICT is embraced in the classroom. Lawson and Comber (1999) stress the need for ongoing support by an ICT coordinator, who is in a good position to guide and successfully integrate ICT at school level.

A final characteristic emerging from the literature regarding ICT integration is 'school culture' (e.g. Kennewell et al. 2000; Tearle 2003), which can be defined as 'the basic assumptions, norms and values, and cultural artefacts that are shared by school members' (Maslowski 2001, pp. 8-9). These meanings and perceptions can be linked to the 'readiness' of a school to adopt the planned change (Tearle 2003), as well as to teachers' actual take-up of ICT (Bennett et al. 2000). Any attempt to improve a school that neglects school culture is, according to Fullan (2001), 'doomed to tinkering' because school culture influences readiness for change. But school culture is complex because it is largely implicit, and can hardly be measured in a direct way (Hargreaves 1994). In the present study, we centre on two other underlying aspects of school culture: 'innovativeness' (Maslowski 2001) and 'goal orientedness' (Staessens \& Vandenberghe 1994). A school's innovativeness reflects the staff's attitude towards educational innovations and to what extent they adapt themselves to changes; goal orientedness reflects to what extent the vision of innovations are clearly formulated and shared by the school members (Devos et al. 2007).

\section{Contextual school characteristics}

In this study, contextual school characteristics related to computer use are limited to access to computers and software. Without adequate recourses, there is little opportunity for teachers to integrate computers into their teaching (Bradley \& Russell 1997). Access is more than simply the availability of computers; it also includes the proper amount and right type of technology available on the sites where teachers and students can use them (Fabry \& Higgs 1997). To achieve an optimum educational impact, each school should base infrastructure decisions on a clear assessment of technical factors and educational needs and objectives. In this context, the authors hypothesize that computer labs are less effective because the physical separation of computer and the actual classroom reduces the optimal chances for ICT integration in learning activities (Salomon 1990; Tondeur et al. in press). Watson (1990) observed that computers in the classroom are a more easily managed resource. As a result, computers are more 
accessible to pupils during learning and instruction and promote more interactive kinds of teaching (Junaid 1996). Despite the advocacy for using computers in the classroom over the existence of computer labs, there is empirical evidence that computer lab settings may be more efficient in learning basic computer skills (e.g. Rule et al. 2002). In this study, a distinction is therefore made between the availability of computers in general and the availability of computers in the physical classroom setting.

\section{Purpose}

As stated earlier, the main research question is: To what extent do individual teacher characteristics and school characteristics influence the adoption of specific types of computer use in Flemish primary education? Considering the theoretical framework, we study the specific influence of cultural and structural/contextual variables at: (1) teacher and (2) school level and in a next step, (3) their combined impact to explain the adoption of the different types of computer use: 'basic computer skills', 'the use of computers as an information tool' and 'the use of computers as a learning tool'.

\section{Research method}

\section{Sample}

Sixty-eight primary schools in Flanders, the Dutch speaking region of Belgium, took part in this study. Mainstream primary education in Flanders is aimed at children from 6 to 12 years old and comprises 6 consecutive years of study. In Flanders, educational policies are characterized by a high level of local school autonomy as to organizing classes and the number of teachers. The majority of schools opt for a year group system. Classes are taught by the same teacher for most classroom subjects during one school year (Ministry of the Flemish Community, Department of Education $2005)^{1}$.

At least one teacher at each grade level was asked to participate, resulting in data from at least six teachers per school. The sample comprises 527 teachers, of which $83.5 \%$ were female. Teacher age range varied from 22 to 64 years, with an average age of 38 (SD = 9.7). In addition, fifty-three ICT coordinators of the same 68 schools were involved in the study. ICT coordi- nators were 36 years old on average $(\mathrm{SD}=9.9)$. Only $21 \%$ of the ICT coordinators were female.

\section{Procedure and instruments}

A questionnaire was developed in order to gather information from teachers about the central dependent variables and about the cultural and structural teacher characteristics presented in Table 1 . In view of the dependent variable, the instrument of Tondeur et al. (2007a) was used to identify the extent to which three different types of computer use were implemented. This instrument builds on the actual types of computer use in Flemish primary education. 'basic computer skills' (three items) identifies the use of computers as a (separate) school subject to teach pupils basic computer skills, such as 'I teach the pupils to make good use of the keyboard and mouse' and 'I teach pupils learning basics of operating systems used at school'. The second and third categories represent educational uses of computers not restricted to its use as a school subject. 'computers as an information tool' (five items) encompasses such aspects as 'The pupils use the computer to select and retrieve information' and 'The pupils use the computer as a demonstration tool'. Emphasis is on researching and processing information and communication. Finally, 'computers as learning tools' (four items) includes items such as 'The pupils use the computer to practice knowledge or skills' and 'The pupils use the computer to elaborate learning content'. The respondents were asked to indicate, on a five-point scale, the extent to which they use the computer for various tasks: $0=$ 'never', $1=$ 'every term', $2=$ 'monthly', $3=$ 'weekly' and $4=$ 'daily'. Control of the psychometric quality of the research instrument reveals a high internal consistency level for 'basic computer skills' $(\alpha=0.80)$, 'computers as an information tool' $(\alpha=0.83)$ and 'computers as learning tools' $(\alpha=0.77)$.

A separate questionnaire for ICT coordinators provided information about contextual and cultural school characteristics (Table 1). Since 2002, all schools in Flanders receive financial support to appoint an ICT coordinator. Their task profile includes both pedagogical and technical support tasks as well as an advisory function to the school board. However, in reality most of the time is devoted to technical aspects of ICT coordination (Ministry of the Flemish Community, Department of Education 2005). ICT coordinators are in the best 
Table 1. School and teacher characteristics as measured in the teacher and information and communication technology (ICT) coordinator surveys.

\begin{tabular}{|c|c|c|c|}
\hline Variable & Short description & Teacher & ICT co-ordinator \\
\hline \multicolumn{4}{|c|}{ Contextual school characteristics } \\
\hline \multirow[t]{3}{*}{ ICT infrastructure } & Availability of computers (with Internet) & $\sqrt{ }$ & \\
\hline & of computers in the classroom (with Internet) & $\sqrt{ }$ & \\
\hline & Pupil/PC-ratio & & $\sqrt{ }$ \\
\hline Software & Availability of software & & $\sqrt{ }$ \\
\hline \multicolumn{4}{|l|}{ Cultural school characteristics } \\
\hline \multirow[t]{2}{*}{ Aspects of school culture } & Goal orientedness (Staessens \& Vandenberghe 1994) & $\sqrt{ }$ & \\
\hline & Innovativeness (Maslowski 2001) & $\sqrt{ }$ & \\
\hline Leadership & Supportive leadership (Hoy \& Tarter 1997) & $\sqrt{ }$ & \\
\hline \multirow[t]{3}{*}{ ICT school policy } & Development ICT school policy (Tondeur et al. in press) & & $\sqrt{ }$ \\
\hline & $\begin{array}{l}\text { Teachers' perceptions ICT school policy (Tondeur et al. } \\
\text { in press) }\end{array}$ & $\sqrt{ }$ & \\
\hline & Content ICT plan (Tondeur et al. in press) & & $\sqrt{ }$ \\
\hline \multirow[t]{2}{*}{ ICT Support } & ICT-related support (Tondeur et al. in press) & & $\sqrt{ }$ \\
\hline & ICT training (extent) & $\sqrt{ }$ & \\
\hline \multicolumn{4}{|c|}{ Structural teacher characteristics } \\
\hline Computer experience & Years of computer experience & $\sqrt{ }$ & \\
\hline Gender & Male/female & $\sqrt{ }$ & \\
\hline \multicolumn{4}{|c|}{ Cultural teacher characteristics } \\
\hline \multirow[t]{2}{*}{ Teaching beliefs } & Traditional teaching beliefs (Woolley et al. 2004) & $\sqrt{ }$ & \\
\hline & Constructivist teaching beliefs (Woolley et al. 2004) & $\sqrt{ }$ & \\
\hline Computer attitudes & General Computer Attitudes (van Braak \& Goeman 2003) & $\sqrt{ }$ & \\
\hline Innovativeness & Teachers' willingness to change (van Braak 2001) & $\sqrt{ }$ & \\
\hline
\end{tabular}

position to provide information about the ICT infrastructure, software, the development of an ICT school policy and ICT-related support.

\section{Data analysis}

Considering the earlier discussion about the integration of ICT, interplay can be assumed between teachers as individuals and the school context to which they belong. This assumption strongly affects the statistical analysis procedures to be adopted when studying ICT integration. In this study, the influence of teacher and school characteristics on different types of educational computer use has been explored by means of multilevel analysis in order to examine teacher-level effects and school effects in the context of one and the same analysis. Whereas linear regression techniques attempt to explain the variation in a dependent variable in terms of one or more independent variables, the adoption of multilevel modelling techniques is helpful to take different levels within a hierarchy of nested variables into account (Goldstein 1995). In the present study, data from teachers (level 1) are not considered as completely independent, because of the school context shared by the teachers in this school (level 2).

In order to determine the differential impact of determinants on the three types of computer use, three models were tested. In this way we could test, for example, if 'innovativeness' is related to the use of 'computers as an information tool' but unrelated to 'basic computer skills' or if 'computers in the classroom' tend to a specific type of computer use. For each model, we initially analysed an unconditional two-level null model with only one intercept term included. This null model permitted partitioning the total variance into within-school and between-school components. Next, we added - step by step - effects of independent variables to the null model to detect their significant contribution to explain the dependent variable computer use. The step-by-step procedure was explicitly based on the variable structure as represented in the framework of Veenstra (1999) that was discussed earlier. An attempt will be made to explain the effects of characteristics from the outer circles by means of characteristics from the inner circles. The parameters of the multilevel model were estimated using the iterative generalized 
Table 2. Unconditional variance components for 'basic computer skills' (CS), 'computers as a learning tool' (LT) and 'the use of computers as an information tool' (IT).

\begin{tabular}{lccc}
\hline & CS & LT & IT \\
\hline $\begin{array}{l}\text { \% of variance between teachers } \\
\text { within schools }\end{array}$ & $82 \%$ & $84 \%$ & $91 \%$ \\
\begin{tabular}{l} 
\% of variance between schools \\
\hline
\end{tabular} & $18 \%$ & $16 \%$ & $9 \%$ \\
\hline
\end{tabular}

least squares estimation procedure made available in the MLwiN software (Centre for Multilevel Modeling, Bristol, UK; Rasbash et al. 2000).

\section{Results}

\section{Null model}

As can be derived from Table 2, the random part of the null models provides justification for the application of multilevel analysis. Both the variances at teacher level and at school level are significantly different from zero for the three types of computer use (Table 3 ). These null models serve as a baseline to compare subsequent, more complex models, and they partition the total variance of educational computer use into between schools and between teachers within schools variance (Table 2).

The largest differences between schools can be observed in 'basic computer skills' (CS). Respectively, $18 \%$ of the total variance in CS is related to differences between schools, whereas the remaining $82 \%$ of the variance may be attributed to differences at teacher level. Sixteen percent of the variance in 'computers as a learning tool' (LT) is related to differences between schools. The least school-to-school differences occur for the 'use of computers as an information tool' (IT).

\section{Final model}

After estimating the null models, school and teacher characteristics were added step by step. As explained earlier, the sequence for entering the structural and cultural variables into the model was based on the framework of Veenstra and Kuyper (2004). The results of these analyses are summarized in Table 3. Since parsimonious models are preferred, only significant predictors that are helpful to improve the model were retained.

First, we consider the effects of contextual school characteristics on the three types of computer use. The variable 'availability of computers' is positively related to the adoption of ICT in view of basic CS, whereas the 'availability computers in the classroom' is positively related to the adoption of ICT as an LT. The 'availability of computers with Internet connection' is, of course, associated with the adoption of ICT as an IT.

Taking the schools' cultural characteristics into account, three variables have a significantly positive effect on CS: 'openness to change', 'perceptions school policy' and 'ICT training'. In contrast, no cultural school characteristics have a significant impact on IT. Significant determinants of LT are 'openness to change' and 'perceptions school policy'. The significant effect of 'supportive leadership' and 'goal-orientedness' seem to disappear when controlling for the 'schools' innovativeness'.

Subsequently, structural teacher characteristics were added to the model. The results highlight the significant effect of 'gender' on the adoption of ICT as an IT. Male teachers report the use of computers as an IT more often as opposed to their female colleagues. Also a significant positive effect was observed for 'computer experience' on CS. No significant effect on LT was found, based on structural teacher characteristics.

Of the cultural teacher characteristics, 'constructivist teaching beliefs' has a significant effect on the adoption of the three types of computer use. The effect on CS and LT is rather small. Only in the adoption of ICT as an IT the positive impact of 'constructivist teaching beliefs' is high. Conversely, 'traditional teaching beliefs' have a significantly negative impact on IT. Finally, 'teachers' innovativeness' has a positive effect on LT and IT and seems to mediate the effect of 'computer attitudes'.

\section{Discussion}

In this study, we explored a variety of teacher and school variables to explain the large differences in computer use as reported by primary school teachers in Flanders. From a methodological perspective, the results demonstrate the need to adopt multilevel modelling in this type of research: we discovered a significant amount of variance attributed at school level to explain differences in the types of computer use. Additionally, the multilevel approach allowed identifying the impact of teacher characteristics in conjunction with school characteristics. In this respect, the study corroborates previous findings (Kennewell et al. 2000; Tearle 2003; 


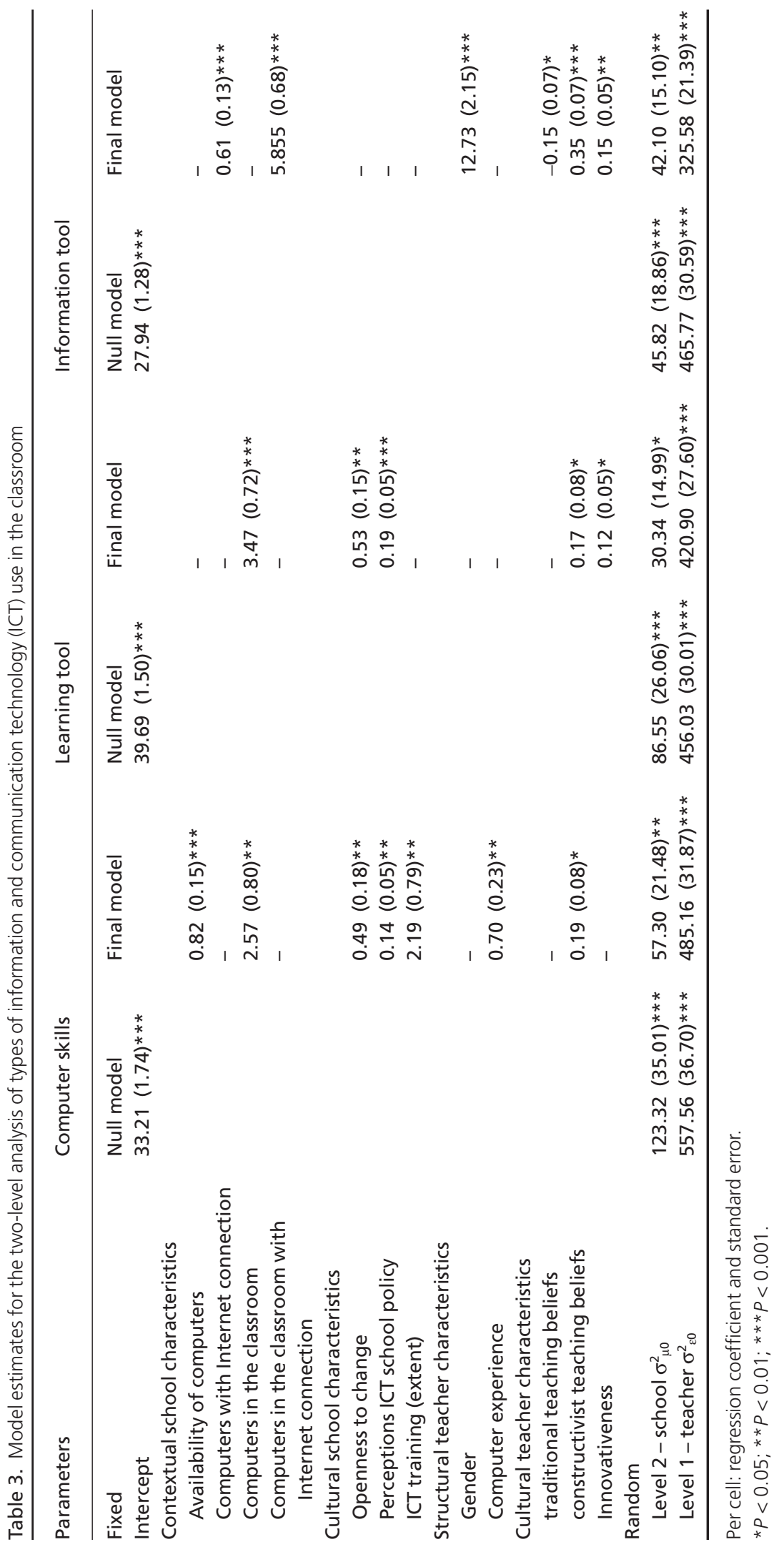


O'Dwyer et al. 2004; Tondeur et al. in press) that have shown the importance to verify the influence of characteristics at school level. Although there is still much to learn with respect to the impact of schools characteristics, the findings presented here indicate that ICT integration does not only depend on the position and behaviour of the individual teachers.

Furthermore, the results confirm the importance of examining ICT integration from a multidimensional perspective (cf. Becker 2001; O'Dwyer et al. 2004; Tondeur et al. 2007a). A clear example is seen with respect to the role of infrastructure. Although infrastructure is an important condition for ICT integration in general, our findings suggest that the location of computer infrastructure in the school and the availability of an Internet connection are associated with specific types of computer use (cf. Salomon 1990; Watson 1990). The results show that the 'availability of computers' is positively related to the adoption of ICT in view of 'basic computer skills' whereas 'availability of computers in the classroom' is positively related to the adoption of ICT as a learning tool. This is in line with research findings pointing to the idea that the specific positioning of computer infrastructure in the classroom might in a specific way foster ICT integration in learning activities (Junaid 1996; Fabry \& Higgs 1997; Tondeur et al. in press). However, the findings of this study do not negate the importance of computer labs to increase basic computer skills (e.g. Rule et al. 2002). In addition, the provision of computers with an Internet connection is needed to foster the use of computers to research and process information. These results have clear policy implications for schools wishing to promote specific types of educational computer use.

In a comparable way, cultural school characteristics are also associated with specific types of computer use. Several cultural school characteristics are significant predictors for 'basic computer skills' and 'computers as a learning tool'. But no cultural school characteristics were detected to explain the use of 'computers as an information tool'. A possible reason for the latter is that 'computers as an information tool' is considered as the most innovative type of computer use and related to learning goals pursued at higher grade levels (Tondeur et al. 2007a). It therefore appears that the adoption of this type of computer use still depends largely on individual teacher characteristics.
In contrast, the results show the importance of ICT school policies for the use of computers to develop computer skills and as a learning tool. It should be stressed, however, that only the teachers' perceptions about their schools' ICT policy have a significant impact. In other words, successful ICT integration becomes much more likely when teachers share the values expressed within the school policy and understand their implications (Kennewell et al. 2000; Tondeur $e t$ al. in press). This falls in line with research findings suggesting that successful ICT integration depends upon the development of a shared vision (Hughes \& Zachariah 2001; Otto \& Albion 2002). The models also show that ICT training is a significant predictor, but only in view of one type of educational computer use: 'basic computer skills'. To build on this positive effect, a school would need to keep professional development at the centre of its ICT policy. However, next to the importance of technical skills development, the analysis of the models urges to adopt a training programme that centres on a wider integration of ICT into the curriculum.

A school's willingness to be innovative is positively related to 'the use the computer as a learning tool', meaning that schools with cultures that are open to innovations move forward with their use of ICT. It is interesting to note that the effect of 'leadership' disappears when controlled for the 'schools' innovativeness'. More research is needed to better understand the relationship between these school characteristics. The absence of an effect of innovativeness (at school level) on 'the use of computers as an information tool' might be surprising. An innovative school culture is not associated with the use of computers as an information tool, whereas, at the same time, teacher innovativeness (at class level) is a significant predictor for this type of computer use. These finding demonstrate the complexity of ICT integration.

At the individual teacher level, we see gender-related differences with regard to the 'use of computers as an information tool'. Shapka and Ferrari (2003) stipulate that gender differences might still exist in the use of less familiar computer applications. This could partially explain why gender differences only exist in the adoption of this type of computer use. One of the cultural teacher characteristics to which we can attribute a strong positive effect is 'constructivist teaching beliefs'. The models presented here suggest that 'constructivist 
teaching beliefs' is a significant predictor for the three different types of computer use - most of all for 'the use of computers as an information tool'. This confirms research findings that constructivist teachers are more likely to use computers in more challenging ways (Becker 2001). According to Ertmer (2005), teachers adopting strong traditionalist beliefs are less likely to use computers in the classroom. Our results suggest, however, that strong traditionalist beliefs decrease only one type of computer use: 'the use of computers as an information tool'. As a result, a multidimensional approach provides more insight into the characteristics affecting computer use.

Although the present study has been helpful to study in depth the impact of an interrelated set of teacher and school variables to explain the differences in computer use, it is important to recognize that the present model is but a first projection of a theoretical framework to describe this complex reality. In addition, the empirical evidence put forward supports the present model, but does actually not 'proof' the model. Future research should therefore adopt an iterative approach in developing the model to explain and evaluating ICT integration in education. First, the results cannot simply be generalized to other educational levels. Some variables were specifically measured in the context of primary education. We have to assume that ICT integration in education can be different outside the Flemish educational context. In this respect, earlier studies (Tawalbeh 2001; Bryderup \& Kowalski 2002; Tondeur et al. 2007b) stressed the importance of national ICT policies in view of subsidizing ICT infrastructure, providing in-service training, etc. This indicates that further refinement and evaluation of the model might be needed outside the Flemish educational context. Next to the level of national school policies, we should also consider the level of the individual pupil (cf. Selwyn \& Bullon 2000; Kerawalla \& Crook 2002; Levin \& Wadmany 2006). The study of Kerawalla and Crook (2002), for instance, demonstrated the unique impact of pupils' views in relation the use of ICT in the classroom, namely, that they can differ from their teachers' view and thus play a mediating role in educational innovations. Another limitation of the study is the quantitative nature of our survey. Additional qualitative studies, based on interviews and/or observations are needed to explore in more detail the reasons why teachers integrate computers in their classrooms (cf. Selwyn
\& Bullon 2000; Tearle 2003; Lim 2007). Finally, future studies are needed to verify how schools are responding to new ICT standards recently legislated by the Flemish government ${ }^{2}$. According to the Ministry of the Flemish Community, Department of Education (2007), the introduction of ICT standards provides an answer to this social demand, outlining what is expected from educational establishments on the ICT front. Since they are relevant for all subject areas, the ICT standards can be labelled as cross-curriculum objectives and developmental objectives (Tondeur et al. 2007b). It will be interesting to explore how these standards affect school policies and, in turn, ICT integration.

\section{Conclusions}

The focus of the present study on the multidimensional interaction of both teacher and school characteristics has been helpful in developing a richer understanding of the complex process of ICT integration. The effect of school characteristics highlights the potential impact of actions and policies at school level, such as the development of a school-wide vision, school-based in-service training and precise considerations as to the nature of computers access in the classroom. The results also indicate that the differential impact on specific types of computer use is to be considered. Variables at teacher and/or at school level are related to different types of computer use.

\section{Notes}

${ }^{1}$ More information about the Flemish educational context available from: http:// www.ond.vlaanderen.be/English

${ }^{2}$ More information about the new ICT standards is available from http://www. ond.vlaanderen.be/ict/english/competencies_knowlegde_society.pdf

\section{References}

Ainley J., Banks D. \& Fleming M. (2002) The influences of IT: perspectives from five Australian schools. Journal of Computer Assisted Learning 18, 395-404.

Albirini A. (2006) Teachers' attitudes towards information and communication technologies: the case of Syrian EFL teachers. Computers \& Education 47, 373-398.

Anderson R.E. \& Dexter S.L. (2000) School Technology Leadership: Incidence and Impact. (Rep. No. 6). Center for Research on Information Technology and Organizations, University of California, Irvine, Irvine, CA, and University of Minnesota, Minneapolis, MN. 
Baylor A.L. \& Ritchie D. (2002) What factors facilitate teacher skill, teacher morale, and perceived student learning in technology-using classrooms? Computers \& Education 39, 395-414.

Beach R.H. \& Lindahl R. (2004) Identifying the knowledge base for school improvement. Planning and Changing 35, 2-32.

Becker H.J. (2001) How Are Teachers Using Computers in Instruction? Paper presented at the Annual Meeting of the American Educational Researchers Association, Seattle, 10-14 April 2001.

Bennett N., Crawford M., Levacic R., Glover D. \& Earley P. (2000) The reality of school development planning in the effective primary school: technicist or guiding plan? School Leadership and Management 20, 333-351.

Bovée C., Voogt J. \& Meelissen M. (2007) Computer attitudes of primary and secondary students in South Africa. Computers in Human Behavior 23, 1762-1776.

Bradley G. \& Russell G. (1997) Computer experience, school support and computer anxieties. Educational Psychology 17, 267-284.

Bryderup I.M. \& Kowalski K. (2002) The role of local authorities in the integration of ICT in learning. Journal of Computer Assisted Learning 18, 470-479.

Dawson C. \& Rakes G.C. (2003) The influence of principals' technology training on the integration of technology into schools. Journal of Research on Technology in Education 36, 29-49.

Devos G., Bouckenooghe D., Engels N., Hotton G. \& Aelterman A. (2007) An assessment of well-being of principals in Flemish primary schools. Journal of Educational Administration 45, 33-61.

Ertmer P.A. (2005) Teacher pedagogical beliefs: the final frontier in our quest for technology integration? Educational Development Research and Development 53, 25-39.

Fabry D.L. \& Higgs J.R. (1997) Barriers to the effective use of technology in education: current status. Journal of Educational Computing Research 17, 385-395.

Fullan M. (2001) The New Meaning of Educational Change. RoutledgeFarmer, London.

Galanouli D., Murphy C. \& Gardner J. (2004) Teachers' perceptions of the effectiveness of ICT-competence training. Computers \& Education 43, 63-79.

Goldstein H. (1995) Multilevel Statistical Models, 2nd edition. Edward Arnold, London.

Hargreaves A. (1994) Changing Teachers, Changing Times. Cassell, London.

Hoy W.K. \& Tarter C.J. (1997) The Road to Open and Healthy Schools: A Handbook for Change. Corwinn Press, Thousand Oaks, CA.
Huberman M. (1988) Teachers' careers and school improvements. Journal of Curriculum Studies 20, 119-132.

Hughes M. \& Zachariah S. (2001) An investigation into the relationship between effective administrative leadership styles and the use of technology. International Electronic Journal for Leadership in Learning 5, 1-10.

Junaid N. (1996) Instructional labs: pluses and minuses. Proceedings of the Mid-South Instructional Technology Conference 1, 337-346.

Kennewell S., Parkinson J. \& Tanner H. (2000) Developing the ICT Capable School. RouteledgeFalmer, London.

Kent N. \& Facer K. (2004) Different worlds. A comparison of young people's home and school ICT use. Journal of Computer Assisted Learning 20, 440-455.

Kerawalla L. \& Crook C. (2002) Children's computer use at home and at school: context and continuity. British Education Research Journal 22, 751-771.

Kozma R., ed. (2003) Technology, Innovation and Educational Change: A Global Perspective. Information Society for Technology in Education [ISTE] Publications, Eugene, OR.

Lai K.W. \& Pratt K. (2004) Information and communication technology (ICT) in secondary schools: the role of the computer coordinator. British Journal of Educational Technology 35, 461-475.

Lawson T. \& Comber C. (1999) Superhighways technology: personnel factors leading to successful integration of information and communication technology in schools and colleges. Journal of Information Technology for Teacher Education 8, 41-53.

Levin T. \& Wadmany R. (2006) Listening to students' voices on learning with information technologies in a rich technology-based classroom. Journal of Educational Computing Research 34, 295-331.

Lim C.P. (2007) Effective integration of ICT in Singapore schools: pedagogical and policy implication. Educational Technology Research and Development 55, 83-116.

Maslowski R. (2001) School Culture and School Performance: An Explorative Study into the Organizational Culture of Secondary Schools and Their Effects. Twente University Press, Twente, the Netherlands.

Meelissen M.R.M. (2005) ICT: meer voor Wim dan voor Jet? De rol van het basisonderwijs in het aantrekkelijker maken van ICT voor jongens en meisjes. PrintPartners, Enschede, the Netherlands.

Ministry of the Flemish Community, Department of Education. (2005) Education in Flanders. The Flemish Educational Landscape in a Nutshell. Van In, Lier, Belgium.

Ministry of the Flemish Community. Department of Education. (2007) Competences for the Knowledge Society. 
ICT in Education Initiative, 2007-2009. Vlaamse overheid, Brussels. Available at: http://www.ond.vlaanderen.be/ict/ english/competencies_knowlegde_society.pdf (last accessed 16 May 2008).

Niederhauser D.S. \& Stoddart T. (2001) Teachers' instructional perspectives and use of educational software. Teaching and Teacher Education 17, 15-31.

O’Dwyer L.M., Russell M. \& Bebell D.J. (2004) Identifying teacher, school and district characteristics associated with elementary teachers' use of technology: a multilevel perspective. Education Policy Analysis Archives 12, 1-33.

Otto T.L. \& Albion P.R. (2002) Understanding the role of school leaders in realizing the potential of ICTs in education. Paper presented at the International Conference of the Association for the Advancement of Computing in Education, Nashville, TN, 18-23 March 2002.

Rasbash J., Browne W.J., Goldstein H., Yang M., Plewis I., Healy M., Woodhouse G., Draper D., Langford I. \& Lewis T. (2000) A User's Guide to MLwiN (Version 2.1). Institute of Education, University of London, London.

Rasbash J., Steele F. Browne, W. \& Prosser B. (2004) A User's Guide to MLwiN (version 2). Institute of Education, University of London, London.

Rogers E.M. (1995) Diffusion of Innovations. Free Press, New York.

Rozell E.J. \& Gardner W.L. (1999) Computer-related success and failure: a longitudinal field study of the factors influencing computer-related performance. Computers in Human Behavior 15, 1-10.

Rule A.C., Barrera M.T., Dockstader C.J. \& Derr J.A. (2002) Comparing technology skill development in computer lab versus classroom settings of two sixth form grade classes. Journal of Online Interactive Learning 1, 1-11. Available at: http://www.ncolr.org/jiol/issues/PDF/1.1.5.pdf (last accessed 16 May 2008).

Salomon G. (1990) The computer lab: a bad idea now sanctified. Educational Technology 30, 50-52.

Selwyn N. \& Bullon K. (2000) Primary school children's use of ICT. British Journal of Educational Technology 31, 321332.

Shapka J.D. \& Ferrari M. (2003) Computer-related attitudes and actions of teacher candidates. Computers in Human Behavior 19, 319-334.

Shashaani L. (1997) Gender differences in computer attitudes and use among college students. Journal of Educational Computing Research 16, 37-51.

Simpson R.D., Koballa T.R., Jr., Oliver, J.S. \& Crawley F.E. (1994) Research on the affective dimensions of science learning. In Handbook of Research on Science Teaching and Learning (ed. D. White), pp. 211-235. Macmillan, New York.
Song L., Hannafin M.J. \& Hill J.R. (2007) Reconciling beliefs and practices in teaching and learning. Educational Technology Research and Development 55, 27-50.

Staessens K. \& Vandenberghe R. (1994) Vision as a core component in school culture. Journal of Curriculum Studies 26, 187-200.

Stoll L. (1999) Realising our potential: understanding and developing capacity for lasting improvement. School Effectiveness and School Improvement 10, 503-532.

Tan S.C., Hu C., Wong S.K. \& Wettasinghe C.M. (2003) Teacher training on technology-enhanced instruction - a holistic approach. Educational Technology \& Society 6, 96-104.

Tang P.S. \& Ang P.H. (2002) The diffusion of information technology in Singapore schools: a process framework. New Media \& Society 4, 457-478.

Tawalbeh M. (2001) The policy and management of information technology in Jordanian schools. British Journal of Educational Technology 32, 133-140.

Tearle P. (2003) ICT implementation: what makes the difference? British Journal of Educational Technology 34, 567583.

Tondeur J., van Braak J. \& Valcke M. (2007a) Towards a typology of computer use in primary education. Journal of Computer Assisted Learning 23, 197-206.

Tondeur J., van Braak J. \& Valcke M. (2007b) Curricula and the use of ICT in education. British Journal of Educational Technology 38, 962-975.

Tondeur J., van Keer H., van Braak J. \& Valcke M. (2008) ICT integration in the classroom: challenging the potential of a school policy. Computers \& Education 51, 212-223.

van Braak J. (2001) Factors influencing the use of computer mediated communication by teachers in secondary schools. Computers \& Education 36, 41-57.

van Braak J., Tondeur J. \& Valcke M. (2004) Explaining different types of computer use among primary school teachers. European Journal of Psychology of Education 19, 407-422.

van Braak J. \& Goerman K. (2003) Differences between general computer attitudes and perceived computer attributes: development and validation of a scale. Psychological Reports 92, 655-660.

Veenstra R. (1999) Leerlingen-klassen-scholen. Thela Thesis, Amsterdam.

Veenstra R. \& Kuyper H. (2004) Effective students and families: the importance of individual characteristics for achievement in high school. Educational Research and Evaluation 10, 41-70.

Volman M. \& van Eck E. (2001) Gender equity and information technology in education: the second decade. Review of Educational Research 71, 613-634. 
Waite S. (2004) Tools for the job: a report of two surveys of information and communications technology training and use for literacy in primary schools in the West of England. Journal of computer Assisted Learning 20, 11-20.

Watson D. (1990) The classroom vs. the computer room. Computers and Education 15, 33-37.
Woolley S.L., Benjamin W-J. J. \& Woolley A.W. (2004) Construct validity of a self-report measure of teacher beliefs related to constructivist and traditional approaches to teaching and learning. Educational and Psychological Measurement 64, 319-331. 